\title{
EOQ in fuzzy environment and trade credit
}

\author{
Nita H Shah ${ }^{\mathrm{a}^{*}}$, Sarla Pareek ${ }^{\mathrm{b}}$ and Isha Sangal ${ }^{\mathrm{b}}$
}

${ }^{a}$ Department of Mathematics, Gujarat University, Ahmedabad - 380009, Gujarat, India

${ }^{b}$ Centre of Mathematical Sciences, Banasthali University, Banasthali - 304022, Rajasthan, India

\begin{tabular}{l}
\hline A R T I C L E I N F O \\
\hline Article history: \\
Received 6 May 2010 \\
Received in revised form \\
July, 7, 2011 \\
Accepted 7 July 2011 \\
Available online \\
7 July 2011 \\
\hline Keywords: \\
EOQ \\
Trade credit \\
Fuzzy set theory \\
\hline
\end{tabular}

\section{A B S T R A C T}

\begin{abstract}
Now-a-days, the offer of credit period to the retailer for settling the account for the units purchased by the supplier is considered to be the most beneficial policy. In this article, an attempt is made to formulate an economic order quantity model under fuzzy environment where delay in payment for the retailer is permissible. The demand rate, ordering cost and selling price per item are taken as triangular fuzzy numbers. The $\alpha$-cut representation method is used to calculate the optimum cycle time and total optimum cost. The optimum cycle time and total optimum cost in fuzzy sense is de-fuzzified using the centre of gravity method.
\end{abstract}

C 2012 Growing Science Ltd. All rights reserved

\section{Introduction}

In global market, supplier uses trade credit as a promotion tool to increase his sale and attract new retailers. Therefore, in practice, the supplier will allow a certain fixed period (credit period) for settling the amount that the supplier owe to retailer for the items supplied. Before the end of the trade credit period, the retailer can sell the goods, accumulate revenue, and earn interest. A higher interest is charged if the payment is not settled by the end of the trade credit period. Goyal (1985) first studied an EOQ model under the conditions of permissible delay in payments. Shah (1993a, 1993b), Aggarwal and Jaggi (1995), Hwang and Shinn (1997) extended Goyal's (1985) model to consider the deterministic inventory model with a constant deterioration rate. Shinn et al. (1996) extended Goyal's (1985) model and considered quantity discount for freight cost. Jamal et al. (1997) extended Aggarwal and Jaggi (1995) model to allow for shortages.

Chung (1998) presented the discounted cash flow (DCF) approach for the analysis of the optimal inventory policy in the presence of trade credit. Shah and Shah (1998) developed a probabilistic inventory model when delay in payment is permissible. Jamal et al. (2000) and Sarker et al. (2000) computed interest earned on the selling price and concluded that the retailer should settle his account relatively sooner as the unit-selling price increases relative to the unit purchase cost. Chang and Dye (2001) extended the model of Jamal et al. (1997) for time dependent deterioration. 
Teng (2002) proved that it is beneficial for a well-established retailer to put order of smaller size and take the benefits of the permissible delay more frequently. Shinn and Hwang (2003) determined the retailer's optimal price and order size simultaneously under the condition of order-size-dependent delay in payment. Huang and Chung (2003) extended Goyal's (1985) model to discuss the replenishment and payment policies to minimize the annual total average cost under cash discount and payment delay from the retailer's point of view. Teng et al. (2005) developed the optimal pricing and lot sizing under permissible delay in payments by considering the difference between selling price and purchase quantity and demand to be price sensitive. Yang-Fu Huang's (2007) developed easy to use procedure to find the optimal ordering policy for the retailer.

Usually researchers consider different parameters of an inventory model either as constant or dependent on time or probabilistic nature for the development of the economic order quantity model. However, in the real life situations, these parameters may have little deviations from the exact value, which may not follow any probability distribution. In these situations, if these parameters are treated as fuzzy parameters, then it will be more realistic. These types of problems are de-fuzzified first using a suitable fuzzy technique and then the solution procedure can be obtained in the usual manner. Several authors, namely Chang et al. (1998), Lee and Yao (1998), Lin and Yao (2000), Yao et al. (2000), De, Kundu and Goswami (2003), De and Goswami (2006) and Gani and Maheswari (2010) developed inventory models in fuzzy sense by considering different parameters as fuzzy parameters.

In this article, we propose an economic order quantity model under the condition of permissible delay in payments in the fuzzy sense. The demand rate, ordering cost and selling price per item may be flexible with some vagueness for their values. In real life situations, all these parameters in an inventory model are uncertain, imprecise and the determination of optimum cycle time becomes a non-stochastic vague decision-making process. In this situation, a suitable way to model these imprecise data is to use fuzzy sets, and to formulate the model in a fuzzy environment. We use the centre of gravity method for defuzzifying fuzzy total average cost. Numerical examples are used to illustrate the results given in this paper.

\section{Assumptions and Notations}

The proposed mathematical model is based on the following assumptions:

(a) The inventory system under consideration deals with a single item.

(b) Replenishment rate is infinite.

(c) Shortages are not allowed.

(d) The lead-time is zero or negligible.

(e) Unit selling price is greater than unit purchasing price.

(f) The supplier offers the retailer a credit period of (say) $M$-days. During this time, the retailer deposits generated revenue in an interest bearing account. At the end of this period, the retailer pays off all units sold, keeping the rest for day-to-day expenses and starts paying for the interest charges on the unsold stock. In addition, the following notations are used throughout this paper:

\footnotetext{
$R \quad$ annual constant demand

$\widetilde{R} \quad$ fuzzy annual demand

A ordering cost per order

$\tilde{A} \quad$ fuzzy ordering cost

$P \quad$ selling price per unit

$\widetilde{P} \quad$ fuzzy unit selling price
} 
C unit purchase cost

$h \quad$ unit inventory holding cost per year excluding the interest charges

Q order quantity

$M \quad$ the offered trade credit by the supplier to the retailer to settle the account

$I_{c} \quad$ interest charged per $\$$ in stock per year by the supplier

$I_{e} \quad$ interest earned per $\$$ per year by the retailer

$T \quad$ cycle time

$q(t)$ the inventory level at any instant of time $t, 0 \leq t \leq T$

$K_{1}(T)$ the total relevant cost per unit time when $M \leq T$

$K_{2}(T)$ the total relevant cost per unit time when $M \geq T$

$\tilde{K}_{1}(T)$ fuzzy total relevant cost per unit time when $M \leq T$

$\tilde{K}_{2}(T)$ fuzzy total relevant cost per unit time when $M \geq T$

$U\left(\tilde{K}_{1}(T)\right)$ defuzzified value of fuzzy total cost $\tilde{K}_{1}(T)$

$U\left(\tilde{K}_{2}(T)\right)$ defuzzified value of fuzzy total cost $\tilde{K}_{2}(T)$

$T_{1} \quad$ the total cycle time when $M \leq T$

$T_{2} \quad$ the total cycle time when $M \geq T$

$\tilde{T}_{1} \quad$ fuzzy total cycle time when $M \leq T$

$\tilde{T}_{2} \quad$ fuzzy total cycle time when $M \geq T$

$U\left(\tilde{T}_{1}\right)$ defuzzified value of fuzzy total cycle time $\tilde{T}_{1}$

$U\left(\tilde{T}_{2}\right)$ defuzzified value of fuzzy total cycle time $\tilde{T}_{2}$

\section{Crisp Mathematical Model}

Let $q(t)$ be the inventory level at any time $t(0 \leq t \leq T)$. Initially, the stock level is $Q$. Now, the cost of placing an order,

OC $=\frac{A}{T}$.

The inventory holding cost per cycle,

$I H C=\frac{h R T}{2}$.

Regarding interest charged and interest earned we have the following two cases depending on the lengths of $T$ and $M$.These two cases are graphed in Fig. 1.
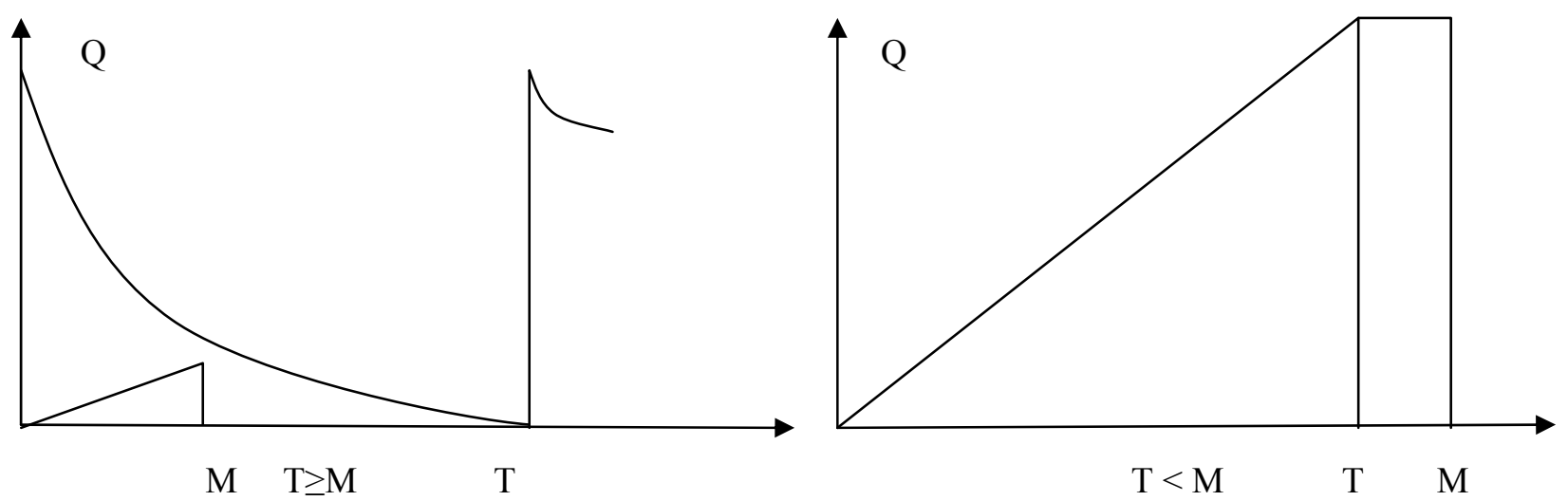

Fig. 1. The inventory - time graph 


\section{Case-1: $M \leq T$}

During the credit period, the retailer sells items and deposits the generated revenue into an amount bearing account at the interest rate $I_{e}$ per dollar per year. Therefore, the interest earned per unit time is,

$I E_{1}=\frac{P I_{e}}{T} \int_{0}^{M} R t d t=\frac{P I_{e} R M^{2}}{2 T}$.

The unsold items in stock are charged at interest rate $I_{c}$ by the supplier at the beginning of time $T$. Therefore, the interest charged per unit time is,

$$
I C_{1}=\frac{C I_{c}}{T} \int_{M}^{T} R(T-t) d t=\frac{C I_{c} R(T-M)^{2}}{2 T} .
$$

Hence, the total cost per time unit is,

$$
K_{1}(T)=O C+I H C+I C_{1}-I E_{1}
$$

\section{Case-2: $M \geq T$}

In this case, the retailer sells $R T$ units by the end of the cycle time and has CRT in his account to pay the supplier in full by the end of the credit period $M$. Hence, the interest earned per unit time is,

$$
I E_{2}=\frac{P I_{e}}{T}\left[\int_{0}^{T} R t d t+Q(M-T)\right]=\frac{P I_{e}}{T}\left[\frac{R T^{2}}{2}+R T(M-T)\right]=P I_{e} R\left(M-\frac{T}{2}\right) .
$$

Hence, the total cost per unit time is,

$$
K_{2}(T)=O C+I H C-I E_{2} .
$$

Hence, the total relevant cost $K(T)$ per time unit is,

$$
K(T)=\left\{\begin{array}{l}
K_{1}(T), M \leq T \\
K_{2}(T), M \geq T
\end{array}\right.
$$

where,

$$
K_{1}(T)=\frac{A}{T}+\frac{h R T}{2}+\frac{C I_{c} R(T-M)^{2}}{2 T}-\frac{P I_{e} R M^{2}}{2 T}=\frac{A}{T}+\frac{h R T}{2}+\frac{C I_{c} R T}{2}+\frac{C I_{c} R M^{2}}{2 T}-C I_{c} R M-\frac{P I_{e} R M^{2}}{2 T},
$$

and

$$
K_{2}(T)=\frac{A}{T}+\frac{h R T}{2}-P I_{e} R\left(M-\frac{T}{2}\right) .
$$

One can easily check that, $K_{1}(M)=K_{2}(M)$. So $K(T)$ is continuous function of $T$. Corresponding to the cost $K_{1}(T)$, optimal cycle time $T_{1}$ is obtained by taking the first-order and second-order derivative of Eq. (9) with respect to $T$. We obtain, 
$\frac{d K_{1}(T)}{d T}=-\frac{A}{T^{2}}+\frac{h R}{2}+\frac{C I_{c} R}{2}-\frac{C I_{c} R M^{2}}{2 T^{2}}+\frac{P I_{e} R M^{2}}{2 T^{2}}$.

and

$\frac{d^{2} K_{1}(T)}{d T^{2}}=\frac{2 A}{T^{3}}+\frac{C I_{c} R M^{2}}{T^{3}}-\frac{P I_{e} R M^{2}}{T^{3}}>0$.

For the optimal cycle time $T_{1}$, let $\frac{d K_{1}(T)}{d T}=0$, which gives

$T_{1}=\sqrt{\frac{2 A+R M^{2}\left(C I_{c}-P I_{e}\right)}{R\left(h+C I_{c}\right)}}$.

Now, corresponding to the cost $K_{2}(T)$, optimal cycle time $T_{2}$ is found out by taking the first-order and second-order derivative of equation (10) with respect to $T$. We obtain,

$\frac{d K_{2}(T)}{d T}=-\frac{A}{T^{2}}+\frac{h R}{2}+\frac{P I_{e} R}{2}$,

and

$\frac{d^{2} K_{2}(T)}{d T^{2}}=\frac{2 A}{T^{3}}>0$

Therefore, for the optimal cycle time $T_{2}, \frac{d K_{2}(T)}{d T}=0$, which gives

$T_{2}=\sqrt{\frac{2 A}{R\left(h+P I_{e}\right)}}$.

\section{Fuzzy Methodology}

Here $A, R$ and $P$ are not known precisely and let $A, R$ and $P$ be defined by triangular fuzzy numbers such that

$$
\tilde{A}=\left[a_{1}, a_{2}, a_{3}\right], \tilde{R}=\left[r_{1}, r_{2}, r_{3}\right] \text { and } \tilde{P}=\left[p_{1}, p_{2}, p_{3}\right] \text {, }
$$

where $\left(a_{1}<a_{2}<a_{3}\right),\left(r_{1}<r_{2}<r_{3}\right)$ and $\left(p_{1}<p_{2}<p_{3}\right)$ based on subjective judgments. We apply arithmetic operators based on fuzzy quantities and then defuzzify the same to convert them into crisp output.

The membership functions for $\widetilde{A}, \widetilde{R}$ and $\widetilde{P}$ are defined as follow :

$\mu_{\tilde{A}}(\tilde{A})=\left\{\begin{array}{ll}0 & \text {,if } A<a_{1} \\ \frac{A-a_{1}}{a_{2}-a_{1}}, \text { if } a_{1} \leq A<a_{2} \\ \frac{a_{3}-A}{a_{3}-a_{2}}, \text { if } a_{2} \leq A<a_{3} \\ 0 \quad \text {,if } A \geq a_{3}\end{array} \quad\left(\right.\right.$ I) $\quad \mu_{\tilde{R}}(\tilde{R})=\left\{\begin{array}{ll}0 & \text {,if } R<r_{1} \\ \frac{R-r_{1}}{r_{2}-r_{1}}, \text { if } r_{1} \leq R<r_{2} \\ \frac{r_{3}-R}{r_{3}-r_{2}}, \text { if } r_{2} \leq R<r_{3} \\ 0 \quad \text {,if } R \geq r_{3}\end{array} \quad\right.$ (II) $\quad \mu_{\tilde{P}}(\tilde{P})= \begin{cases}0 & \text {,if } P<p_{1} \\ \frac{P-p_{1}}{p_{2}-p_{1}} & \text {,if } p_{1} \leq P<p_{2} \\ \frac{p_{3}-P}{p_{3}-p_{2}} & \text {,if } p_{2} \leq P<p_{3} \\ 0 & \text {,if } P \geq p_{3}\end{cases}$

Now using the concept of ' $\alpha$-cut' method, we see from (I), (II), (III),

$$
{ }^{\alpha} A=\left[\alpha\left(a_{2}-a_{1}\right)+a_{1}, a_{3}-\alpha\left(a_{3}-a_{2}\right)\right] \text { for } \alpha \in[0,1],
$$




$$
\begin{array}{ll}
{ }^{\alpha} R=\left[\alpha\left(r_{2}-r_{1}\right)+r_{1}, r_{3}-\alpha\left(r_{3}-r_{2}\right)\right] & \text { for } \alpha \in[0,1], \\
{ }^{\alpha} P=\left[\alpha\left(p_{2}-p_{1}\right)+p_{1}, p_{3}-\alpha\left(p_{3}-p_{2}\right)\right] & \text { for } \alpha \in[0,1] .
\end{array}
$$

Then these fuzzy quantities are de-fuzzified to a crisp value by the 'centre of gravity' method.

\section{Fuzzy Inventory model}

In the fuzzy environment, we assume that the demand rate, ordering cost and selling price are fuzzy numbers and denoted by $\widetilde{R}, \widetilde{A}$ and $\widetilde{P}$ respectively. Here, we assume that $\tilde{R}=\left[r_{1}, r_{2}, r_{3}\right], \tilde{A}=\left[a_{1}, a_{2}, a_{3}\right]$ and $\tilde{P}=\left[p_{1}, p_{2}, p_{3}\right]$ are non-negative triangular fuzzy numbers.

\subsection{Derivation of $\tilde{K}_{1}(T)$ and $\tilde{K}_{2}(T)$}

The fuzzy annual total relevant cost can be expressed as,

$$
\tilde{K}(T)=\left\{\begin{array}{l}
\tilde{K}_{1}(T), M \leq T \\
\tilde{K}_{2}(T), M \geq T
\end{array}\right.
$$

where

$$
\begin{aligned}
& \tilde{K}_{1}(T)=X_{11} \tilde{A}+X_{12} \tilde{R}+X_{13} \tilde{P} \tilde{R}, \\
& \tilde{K}_{2}(T)=X_{21} \tilde{A}+X_{22} \tilde{R}+X_{23} \tilde{P} \tilde{R},
\end{aligned}
$$

where $X_{11}=X_{21}=\frac{1}{T}, X_{12}=\frac{h T}{2}+\frac{C I_{c}}{2}\left[T+\frac{M^{2}}{T}-2 M\right], X_{13}=-\frac{I_{e} M^{2}}{2 T}, X_{22}=\frac{h T}{2}$ and $X_{23}=I_{e}\left[\frac{T}{2}-M\right]$. Then using the concept of ' $\alpha$-cut' method for $\tilde{K}_{1}(T)$ we get,

$$
\begin{aligned}
{ }^{\alpha}\left[\tilde{K}_{1}(T)\right] & ={ }^{\alpha}\left[X_{11} \tilde{A}+X_{12} \tilde{R}+X_{13} \tilde{P} \tilde{R}\right] \\
& =\left[\begin{array}{l}
X_{11}\left\{\alpha\left(a_{2}-a_{1}\right)+a_{1}\right\}+X_{12}\left\{\alpha\left(r_{2}-r_{1}\right)+r_{1}\right\}+X_{13}\left\{\alpha\left(p_{2}-p_{1}\right)+p_{1}\right\}\left\{\alpha\left(r_{2}-r_{1}\right)+r_{1}\right\}, \\
X_{11}\left\{a_{3}-\alpha\left(a_{3}-a_{2}\right)\right\}+X_{12}\left\{r_{3}-\alpha\left(r_{3}-r_{2}\right)\right\}+X_{13}\left\{p_{3}-\alpha\left(p_{3}-p_{2}\right)\right\}\left\{r_{3}-\alpha\left(r_{3}-r_{2}\right)\right\} .
\end{array}\right]
\end{aligned}
$$

We put $\alpha=0$ and $\alpha=1$ in Eq. (20) and obtain an approximate triangular fuzzy number for $\tilde{K}_{1}(T)$ as below:

$\tilde{K}_{1}(T)=\left[X_{11} a_{1}+X_{12} r_{1}+X_{13} p_{1} r_{1}, X_{11} a_{2}+X_{12} r_{2}+X_{13} p_{2} r_{2}, X_{11} a_{3}+X_{12} r_{3}+X_{13} p_{3} r_{3}\right]=\left[k_{11}, k_{12}, k_{13}\right],$,

where $k_{11}=X_{11} a_{1}+X_{12} r_{1}+X_{13} p_{1} r_{1}, k_{12}=X_{11} a_{2}+X_{12} r_{2}+X_{13} p_{2} r_{2}$ and $k_{13}=X_{11} a_{3}+X_{12} r_{3}+X_{13} p_{3} r_{3}$.

Thus, the membership function for $\tilde{K}_{1}(T)$ is given as:

$\mu_{\tilde{K}_{1}}\left(\tilde{K}_{1}\right)= \begin{cases}0 & \text {,if } K_{1}<k_{11} \\ \frac{K_{1}-k_{11}}{k_{12}-k_{11}}, & \text { if } k_{11} \leq K_{1}<k_{12} \\ \frac{k_{13}-K_{1}}{k_{13}-k_{12}} & \text {, if } k_{12} \leq K_{1}<k_{13} \\ 0 & \text {,if } K_{1} \geq k_{13}\end{cases}$ 
$\tilde{K}_{1}(T)$ is de-fuzzified to a crisp value by the 'center of gravity' method. The de-fuzzified $\tilde{K}_{1}(T)$ is found as,

$\mu\left(\tilde{K}_{1}(T)\right)=\operatorname{defuzz}\left(\tilde{K}_{1}(T)\right)=\frac{\int_{R} \tilde{K}_{1}(T) \mu_{\tilde{K}_{1}}\left(\tilde{K}_{1}(T)\right) d \tilde{K}_{1}(T)}{\int_{R} \mu_{\tilde{K}_{1}}\left(\tilde{K}_{1}(T)\right) d \tilde{K}_{1}(T)}$.

Similarly, using the concept of ' $\alpha$-cut' method for $\tilde{K}_{2}(T)$ yields the following,

$$
\begin{aligned}
{ }^{\alpha}\left[\tilde{K}_{2}(T)\right] & ={ }^{\alpha}\left[X_{21} \tilde{A}+X_{22} \tilde{R}+X_{23} \tilde{P} \tilde{R}\right] \\
& =\left[\begin{array}{l}
X_{21}\left\{\alpha\left(a_{2}-a_{1}\right)+a_{1}\right\}+X_{22}\left\{\alpha\left(r_{2}-r_{1}\right)+r_{1}\right\}+X_{23}\left\{\alpha\left(p_{2}-p_{1}\right)+p_{1}\right\}\left\{\alpha\left(r_{2}-r_{1}\right)+r_{1}\right\}, \\
X_{21}\left\{a_{3}-\alpha\left(a_{3}-a_{2}\right)\right\}+X_{22}\left\{r_{3}-\alpha\left(r_{3}-r_{2}\right)\right\}+X_{23}\left\{p_{3}-\alpha\left(p_{3}-p_{2}\right)\right\}\left\{r_{3}-\alpha\left(r_{3}-r_{2}\right)\right\}
\end{array}\right]
\end{aligned}
$$

We put $\alpha=0$ and $\alpha=1$ in Eq. (23) and obtain an approximate triangular fuzzy number for $\tilde{K}_{2}(T)$ as below:

$\tilde{K}_{2}(T)=\left[X_{21} a_{1}+X_{22} r_{1}+X_{23} p_{1} r_{1}, X_{21} a_{2}+X_{22} r_{2}+X_{23} p_{2} r_{2}, X_{21} a_{3}+X_{22} r_{3}+X_{23} p_{3} r_{3}\right]=\left[k_{21}, k_{22}, k_{23}\right]$,

where $k_{21}=X_{21} a_{1}+X_{22} r_{1}+X_{23} p_{1} r_{1}, k_{22}=X_{21} a_{2}+X_{22} r_{2}+X_{23} p_{2} r_{2}$ and $k_{23}=X_{21} a_{3}+X_{22} r_{3}+X_{23} p_{3} r_{3}$.

Thus, the membership function for $\tilde{K}_{2}(T)$ is given as:

$$
\mu_{\tilde{K}_{2}}\left(\tilde{K}_{2}\right)= \begin{cases}0 & \text {,if } K_{2}<k_{21} \\ \frac{K_{2}-k_{21}}{k_{22}-k_{21}} & \text {,if } k_{21} \leq K_{2}<k_{22} \\ \frac{k_{23}-K_{2}}{k_{23}-k_{22}} & \text {, if } k_{22} \leq K_{2}<k_{23} \\ 0 & \text {,if } K_{2} \geq k_{23}\end{cases}
$$

$\tilde{K}_{2}(T)$ is de-fuzzified to a crisp value by the 'center of gravity' method. The de-fuzzified $\tilde{K}_{2}(T)$ is found as,

$$
\mu\left(\tilde{K}_{2}(T)\right)=\operatorname{defuzz}\left(\tilde{K}_{2}(T)\right)=\frac{\int_{R} \tilde{K}_{2}(T) \mu_{\tilde{K}_{2}}\left(\tilde{K}_{2}(T)\right) d \tilde{K}_{2}(T)}{\int_{R} \mu_{\tilde{K}_{2}}\left(\tilde{K}_{2}(T)\right) d \tilde{K}_{2}(T)} .
$$

\subsection{Derivation of $\tilde{T}_{1}$ and $\tilde{T}_{2}$}

The fuzzy total cycle time can be expressed as,

$$
\tilde{T}=\left\{\begin{array}{l}
\tilde{T}_{1}, M \leq T \\
\tilde{T}_{2}, M \geq T
\end{array}\right.
$$

where

$$
\tilde{T}_{1}=\sqrt{\frac{2 \tilde{A}+\tilde{R} M^{2}\left(C I_{c}-\tilde{P} I_{e}\right)}{\tilde{R}\left(h+C I_{c}\right)}}
$$


$\tilde{T}_{2}=\sqrt{\frac{2 \tilde{A}}{\tilde{R}\left(h+\tilde{P} I_{e}\right)}}$

From inequality, $\left\{\frac{a_{3}-\alpha\left(a_{3}-a_{2}\right)}{\alpha\left(r_{2}-r_{1}\right)+r_{1}}\right\} \geq\left\{\frac{\alpha\left(a_{2}-a_{1}\right)+a_{1}}{r_{3}-\alpha\left(r_{3}-r_{2}\right)}\right\}$ for $\alpha \in[0,1]$, we have

$$
\left\{\frac{\tilde{A}}{\tilde{R}}\right\}=\left[\left\{\frac{\alpha\left(a_{2}-a_{1}\right)+a_{1}}{r_{3}-\alpha\left(r_{3}-r_{2}\right)}\right\},\left\{\frac{a_{3}-\alpha\left(a_{3}-a_{2}\right)}{\alpha\left(r_{2}-r_{1}\right)+r_{1}}\right\}\right] .
$$

Then using the concept of ' $\alpha$-cut' method for $\tilde{T}_{1}$ and we get,

$$
{ }^{\alpha}\left[\tilde{T}_{1}\right]=\left[\sqrt[\alpha]{\frac{2 \tilde{A}+\tilde{R} M^{2}\left(C I_{c}-\tilde{P} I_{e}\right)}{\tilde{R}\left(h+C I_{c}\right)}}\right]=\left[\begin{array}{l}
\sqrt{\frac{2\left\{\alpha\left(a_{2}-a_{1}\right)+a_{1}\right\}+M^{2}\left\{\alpha\left(r_{2}-r_{1}\right)+r_{1}\right\}\left[C I_{c}-\left\{\alpha\left(p_{2}-p_{1}\right)+p_{1}\right\} I_{e}\right]}{\left\{r_{3}-\alpha\left(r_{3}-r_{2}\right)\right\}\left(h+C I_{c}\right)}} \\
\sqrt{\frac{2\left\{a_{3}-\alpha\left(a_{3}-a_{2}\right)\right\}+M^{2}\left\{r_{3}-\alpha\left(r_{3}-r_{2}\right)\right\}\left[C I_{c}-\left\{p_{3}-\alpha\left(p_{3}-p_{2}\right)\right\} I_{e}\right]}{\left\{\alpha\left(r_{1}\right)+r_{1}\right\}\left(h+C I_{c}\right)}}
\end{array}\right]
$$

We put $\alpha=0$ and $\alpha=1$ in Eq. (29) and obtain an approximate triangular fuzzy number for $\tilde{T}_{1}$ as below:

$$
\tilde{T}_{1}=\left[\sqrt{\frac{2 a_{1}+M^{2} r_{1}\left(C I_{c}-p_{1} I_{e}\right)}{r_{3}\left(h+C I_{c}\right)}}, \sqrt{\frac{2 a_{2}+M^{2} r_{2}\left(C I_{c}-p_{2} I_{e}\right)}{r_{2}\left(h+C I_{c}\right)}}, \sqrt{\frac{2 a_{3}+M^{2} r_{3}\left(C I_{c}-p_{3} I_{e}\right)}{r_{1}\left(h+C I_{c}\right)}}\right]
$$

$=\left[t_{11}, t_{12}, t_{13}\right]$

where $t_{11}=\sqrt{\frac{2 a_{1}+M^{2} r_{1}\left(C I_{c}-p_{1} I_{e}\right)}{r_{3}\left(h+C I_{c}\right)}}, t_{12}=\sqrt{\frac{2 a_{2}+M^{2} r_{2}\left(C I_{c}-p_{2} I_{e}\right)}{r_{2}\left(h+C I_{c}\right)}}, t_{13}=\sqrt{\frac{2 a_{3}+M^{2} r_{3}\left(C I_{c}-p_{3} I_{e}\right)}{r_{1}\left(h+C I_{c}\right)}}$.

Thus, the membership function for $\tilde{T}_{1}$ is given as:

$$
\mu_{\tilde{T}_{1}}\left(\tilde{T}_{1}\right)= \begin{cases}0 & \text {,if } T_{1}<t_{11} \\ \frac{T_{1}-t_{11}}{t_{12}-t_{11}} & \text {,if } t_{11} \leq T_{1}<t_{12} \\ \frac{t_{13}-T_{1}}{t_{13}-t_{12}} & \text {,if } t_{12} \leq T_{1}<t_{13} \\ 0 & \text {,if } T_{1} \geq t_{13}\end{cases}
$$

$\tilde{T}_{1}$ is de-fuzzified to a crisp value by the 'center of gravity' method. The de-fuzzified $\tilde{T}_{1}$ is found as,

$\mu_{\tilde{T}_{1}}\left(\tilde{T}_{1}\right)=\operatorname{defuzz}\left(\tilde{T}_{1}\right)=\frac{\int_{R} \tilde{T}_{1} \mu_{\tilde{T}_{1}}\left(\tilde{T}_{1}\right) d \tilde{T}_{1}}{\int_{R} \mu_{\tilde{T}_{1}}\left(\tilde{T}_{1}\right) d \tilde{T}_{1}}$.

Similarly, using the concept of ' $\alpha$-cut' method for $\tilde{T}_{2}$ and we get, 


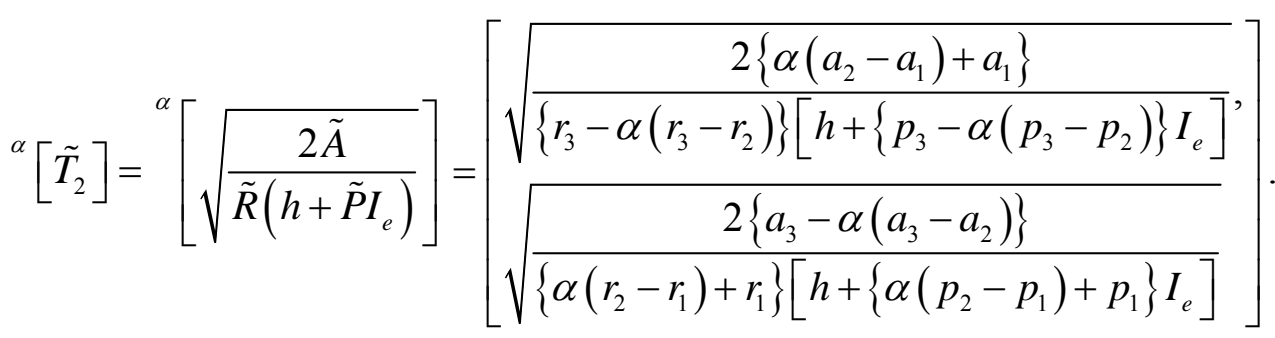

We put $\alpha=0$ and $\alpha=1$ in Eq. (32) and obtain an approximate triangular fuzzy number for $\tilde{T}_{2}$ as below:

$\tilde{T}_{2}=\left[\sqrt{\frac{2 a_{1}}{r_{3}\left(h+p_{3} I_{e}\right)}}, \sqrt{\frac{2 a_{2}}{r_{2}\left(h+p_{2} I_{e}\right)}}, \sqrt{\frac{2 a_{3}}{r_{1}\left(h+p_{1} I_{e}\right)}}\right]=\left[\boldsymbol{t}_{21}, \boldsymbol{t}_{22}, \boldsymbol{t}_{23}\right]$

where $\quad t_{21}=\sqrt{\frac{2 a_{1}}{r_{3}\left(h+p_{3} I_{e}\right)}}, t_{22}=\sqrt{\frac{2 a_{2}}{r_{2}\left(h+p_{2} I_{e}\right)}}$ and $t_{23}=\sqrt{\frac{2 a_{3}}{r_{1}\left(h+p_{1} I_{e}\right)}}$. Thus, the membership function for $\tilde{T}_{2}$ is given as:

$$
\mu_{\tilde{T}_{2}}\left(\tilde{T}_{2}\right)= \begin{cases}0 & \text {,if } T_{2}<t_{21} \\ \frac{T_{2}-t_{21}}{t_{22}-t_{21}} & \text {, if } t_{21} \leq T_{2}<t_{22} \\ \frac{t_{23}-T_{2}}{t_{23}-t_{22}} & \text {, if } t_{22} \leq T_{2}<t_{23} \\ 0 & \text {,if } T_{2} \geq t_{23}\end{cases}
$$

$\tilde{T}_{2}$ is de-fuzzified to a crisp value by the 'centre of gravity' method. The de-fuzzified $\tilde{T}_{2}$ is found as,

$\mu_{\tilde{T}_{2}}\left(\tilde{T}_{2}\right)=\operatorname{defuzz}\left(\tilde{T}_{2}\right)=\frac{\int_{R} \tilde{T}_{2} \mu_{\tilde{T}_{2}}\left(\tilde{T}_{2}\right) d \tilde{T}_{2}}{\int_{R} \mu_{\tilde{T}_{2}}\left(\tilde{T}_{2}\right) d \tilde{T}_{2}}$.

\section{Numerical example}

To illustrate the results of the proposed method, we solve the following numerical example. We use MAPLE (version 11) software for all these calculations.

Let $\widetilde{A}=(48,50,52), \widetilde{R}=(480,500,520)$ be triangular fuzzy numbers.

$h=\$ 5 /$ unit $/$ year,$I_{e}=\$ 0.12 / \$ /$ year,$I_{c}=\$ 0.15 / \$ /$ year,$C=\$ 50 /$ unit .

To find the optimal cycle time (between $T_{1}$ and $T_{2}$ ) and total optimal cost (between $K_{1}\left(T_{1}\right)$ and $K_{2}\left(T_{2}\right)$ ) for different values of $M$, we use the following algorithm. The steps are as follows:

Step-1: Compute $T_{1}$ and $T_{2}$ by solving eq. (31) and (34).

Step-2: If $T_{1} \leq M$, then compute $T_{2}$ and $K_{2}\left(T_{2}\right)$, otherwise go to step-3.

Step-3: If $T_{1}>M$, then compute $K_{1}\left(T_{1}\right)$.

Step-4: Find corresponding cycle time and total optimal cost. 
Table 1

Optimal cycle time and total average cost for different values of $M$

\begin{tabular}{llccc}
\hline$\widetilde{P}$ & & $M=0.04$ year & $M=0.08$ year & $M=0.12$ year \\
\hline \multirow{2}{*}{$(118,120,122)$} & $T_{1}$ & $\mathbf{0 . 1 2 3 0 4 4}$ & $\mathbf{0 . 1 1 1 7 2 3}$ & 0.089726 \\
& $T_{2}$ & 0.101647 & 0.101647 & $\mathbf{0 . 1 0 1 6 4 7}$ \\
& $K_{1}\left(T_{1}\right)$ & $\mathbf{6 1 8 . 4 0 9}$ & 397.716 & 110.419 \\
& $K_{2}\left(T_{2}\right)$ & 696.939 & 408.747 & $\mathbf{1 2 0 . 5 5 6}$ \\
\hline \multirow{3}{*}{$(158,160,162)$} & $T_{1}$ & $\mathbf{0 . 1 2 0 5 1 7}$ & $\mathbf{0 . 1 0 0 1 0 2}$ & 0.050073 \\
& $T_{2}$ & 0.091003 & 0.091003 & $\mathbf{0 . 0 9 1 0 0 3}$ \\
& $K_{1}\left(T_{1}\right)$ & $\mathbf{6 0 2 . 6 3 0}$ & $\mathbf{3 2 5 . 1 4 7}$ & -136.841 \\
& $K_{2}\left(T_{2}\right)$ & 716.027 & 331.836 & $\mathbf{- 5 2 . 3 5 6 7}$ \\
$(180,200,220)$ & $T_{1}$ & $\mathbf{0 . 1 1 7 8 8 2}$ & $\mathbf{0 . 0 8 6 4 0 4}$ & 0.047324 \\
& $T_{2}$ & 0.083464 & 0.083464 & $\mathbf{0 . 0 8 3 4 6 4}$ \\
& $K_{1}\left(T_{1}\right)$ & $\mathbf{5 8 6 . 2 2 0}$ & $\mathbf{2 4 1 . 3 7 3}$ & $\mathbf{- 5 0 8 . 0 4 0}$ \\
& $K_{2}\left(T_{2}\right)$ & 724.258 & 242.341 & $\mathbf{- 2 3 9 . 5 7 9}$ \\
\hline
\end{tabular}

From Table 1 we conclude that, when $M$ is increasing, the optimal cycle time and optimal cost for the retailer is decreasing. In addition, when $P$ is increasing, the optimal time and optimal cost is decreasing. Therefore, from above, we observed that the retailer will not order more quantity to take the benefits of the delay payments more frequently when there is a larger difference between the unit selling price and the unit purchasing price.

\section{Conclusion}

In this paper, we have developed an EOQ model in the fuzzy sense where delay in payments is permissible. The demand rate, ordering cost and selling price are assumed as triangular fuzzy numbers. The fuzzy total variable cost and fuzzy cycle time are derived. By the centre of gravity method, we de-fuzzified the fuzzy total cost and fuzzy cycle time. Numerical example reveals that a higher value of the permissible delay period decreases the total cycle time and total cost of the retailer. It is observed that to avail of delay period facility, the retailer should order frequently and smaller order.

\section{Acknowledgment}

The second and third authors would like to thank DST for support to carry out this research.

\section{References}

Aggarwal, S. P., \& Jaggi, C. K. (1995). Ordering policies of deteriorating items under permissible delay in payments. Journal of Operational Research Society, 46, 658-662.

Chang H. J., \& Dye C. Y. (2001). An inventory model for deteriorating items with partial backlogging and permissible delay in payments. International Journal of Systems Science, 32, 345-352.

Chang, S. C., Yao J. S., \& Lee H. M. (1998). Economic reorder point for fuzzy backorder quantity. European Journal of Operational Research, 109, 183-202.

Chung, K. J. (1998). A theorem on the determination of economic order quantity under conditions of permissible delay in payments. Journal of Information and Optimization Science, 25: 49-52. 
De, S. K., \& Goswami, A. (2006). An EOQ model with fuzzy inflation rate and fuzzy deterioration rate when a delay in payment is permissible. International Journal of Systems Science, 37(5), 323-335.

De, S. K., Kundu, P. K., Goswami, A. (2003). An economic production quantity inventory model involving fuzzy demand rate and fuzzy deterioration rate. Journal of Applied Mathematics and Computing, 12(1-2), 251-260.

Gani, A. N., \& Maheswari, S. (2010). Supply chain model for the retailer's ordering policy under two levels of delay payments in fuzzy environment. Applied Mathematical Sciences, 4(24), 1155 1164.

Goyal, S. K. (1985). Economic order quantity under condition of permissible delay in payments. Journal of Operational Research Society, 36(4), 335-338.

Huang, Y. F. (2007). Supply chain model for the retailer's ordering policy under two levels of delay payments derived algebraically. Opsearch, 44(4), 366-377.

Huang, Y. F., \& Chung K. J. (2003). Optimal replenishment and payment policies in the EOQ model under cash discount and trade credit. Asia Pacific Journal of Operational Research, 20, 177-190.

Hwang, H. \& Shinn, S. W. (1997). Retailer's pricing and lot sizing policy for exponentially deteriorating product under the condition of permissible delay in payments. Computers and Operations Research, 24, 539-547.

Jamal, A. M. M., Sarker B. R., \& Wang S. (1997). An ordering policy for deteriorating items with allowable shortages and permissible delay in payment. Journal of Operational Research Society, 48, 826-833.

Jamal, A. M. M., Sarker B. R., \& Wang S. (2000). Optimal payment time for a retailer under permitted delay of payment by the wholesaler. International Journal of Production Economics, 66, 59-66.

Klir, G., \& Yuan B. (2005). Fuzzy sets and fuzzy logic, theory and applications. Prentice, Hall of India.

Lee, H. M., \& Yao J. S. (1998). Economic production quantity for fuzzy demand quantity and fuzzy production quantity. European Journal of Operational Research, 109, 203-211.

Lee, K. (2005). First Course on Fuzzy Theory and Applications. Springer-Verlag, Berlin Heidelberg.

Lin, D. C., \& Yao, J. S. (2000). Fuzzy economic production for production inventory. Fuzzy Sets and Systems, 111, 465-495.

Sarker B. R., Jamal A. M. M., \& Wang S. (2000). Optimal payment time under permissible delay for products with deterioration. Production Planning \& Control, 11, 380-390.

Shah Nita H. and Shah Y. K. (1998). "A discrete-in-time probabilistic inventory model for deteriorating items under conditions of permissible delay in payments", International Journal of Systems Science, 29: 121-126.

Shah, N. H. (1993-a). A lot - size model for exponentially decaying inventory when delay in payments is permissible", Cahiers du Centre D' Etudes de Recherche Operationnell Operations Research, Statistics and Applied Mathematik, 35, 1-9.

Shah, N. H. (1993-b). A probabilistic order level system when delay in payments is permissible. Journal of the Korean Operations Research and Management Science, 18(2), 175-183.

Shinn S. W., \& Hwang H. (2003). Optimal pricing and ordering policies for retailers under ordersize-dependent delay in payments. Computers and Operations Research, 30, 35-50.

Shinn S. W., Hwang H. P., \& Sung S. (1996). Joint price and lot size determination under conditions of permissible delay in payments and quantity discounts for freight cost. European Journal of Operational Research, 91, 528-542.

Teng J. T. (2002). On the economic order quantity under conditions of permissible delay in payments. Journal of Operational Research Society, 53, 915-918.

Teng J. T., Chang C. T., \& Goyal S. K. (2005). Optimal pricing and ordering policy under permissible delay in payments. International Journal of Production Economics, 97, 121-129.

Yao J. S., Chang S. C., \& Su J. S. (2000). Fuzzy inventory without backorder for fuzzy order quantity and fuzzy total demand quantity. Computer and Operations Research, 27, 935-962. 


\section{Appendix}

Fuzzy set theory: We include a brief introduction on fuzzy set theory. More details are available in Klir et al. (2005) and Lee (2005).

Definition-1 A fuzzy set is a set where the members are allowed to have partial membership and hence the degree of membership varies from 0 to 1 . It is expressed as, $A=\left\{\left(x, \mu_{\widetilde{A}}(x)\right) \mid x \in X\right\}$ where $X$ is the universe of discourse and $\mu_{\widetilde{A}}(x)$ is the universe of discourse and $\mu_{\widetilde{A}}(x)=0$ or 1 i.e., $\mathrm{x}$ is a non-member in $A$ if $\mu_{\widetilde{A}}(x)=0$, and $\mathrm{x}$ is a member in $\mathrm{A}$ if $\mu_{\widetilde{A}}(x)=1$.

Definition-2 If a fuzzy set $\mathrm{A}$ is defined on $\mathrm{X}$, for any $\alpha \in[0,1]$, the $\alpha$-cuts ${ }^{\alpha} A$ is represented by the following crisp set,

$$
\begin{aligned}
& \text { Strong } \alpha-\text { cuts : }{ }^{\alpha+} A=\left\{x \in X \mid \mu_{A}(x)>\alpha\right\}, \alpha \in[0,1] \\
& \text { Weak } \alpha \text {-cuts : }{ }^{\alpha} A=\left\{x \in X \mid \mu_{A}(x) \geq \alpha\right\}, \alpha \in[0,1] .
\end{aligned}
$$

Fuzzy Arithmetic Operations: We define fuzzy arithmetic operations on fuzzy numbers in terms of the $\alpha$-cuts. Let, $\mathrm{A}$ and $\mathrm{B}$ are two fuzzy sets and if ' $*$ ' denotes any of the four basic arithmetic operations $(+,-, *, /)$ then a fuzzy set $Z=(A * B)$ and $Z \in R$, can be defined as, ${ }^{\alpha}(A * B)={ }^{\alpha} A *{ }^{\alpha} B$ such that $\forall \alpha \in(0,1]$.

However, if ' *' is a division operator, then ${ }^{\alpha}(A * B)={ }^{\alpha} A *^{\alpha} B$, such that $\forall \alpha \in(0,1]$ and $0 \notin^{\alpha} B$.

\section{Theorem-1 (First decomposition theorem)}

For every $A \in X$,

$$
A=\bigcup_{\alpha \in(0,1]} A, \text { where, }{ }_{\alpha} A(x)=\alpha_{\alpha} A(x)
$$

From first decomposition theorem, if $Z=(A * B)$ and $Z \in R$,

$$
(A * B)=\bigcup_{\alpha \in(0,1]}(A * B) \text {. }
$$

Since ${ }^{\alpha}(A * B)$ is a closed interval for each $\alpha \in(0,1]$ with both A and B fuzzy, $(A * B)$ is also a fuzzy number.

Definition-3 For the de-fuzzification of a fuzzy set to a crisp value, 'centre of gravity' or 'moment method' is a popular and efficient approach. $\widetilde{A}(x)$ is converted to a crisp value by the following operation,

$$
A=\operatorname{defuzz}(\widetilde{A})=\frac{\int_{R} A \mu_{\widetilde{A}}(x) d x}{\int_{R} \mu_{\widetilde{A}}(x) d x}
$$

